\title{
O terraplanismo e o apelo à experiência pessoal como critério epistemológico ${ }^{+}$
}

\author{
Fábio Marineli ${ }^{1}$ \\ Universidade Federal de Lavras \\ Lavras - MG
}

\section{Resumo}

Movimentos negacionistas vêm ganhando destaque nos últimos anos, disseminados principalmente pelas mídias sociais. A crescente receptividade às suas ideias, assim como a notícias com conteúdos inverídicos, pode ser apontada como indício de uma crise epistemológica relacionada à perda de confiança nas instituições fundamentais da sociedade, na ciência inclusive. As pessoas descrentes nessas instituições tornam-se cada vez mais dependentes das próprias experiências e crenças, até mesmo para avaliar aquilo que se encontra no campo científico. Neste trabalho abordamos uma das características do movimento terraplanista atual: o apelo à experiência pessoal como critério epistemológico incontestável. Para tanto, apoiamo-nos sobretudo nas discussões desenvolvidas por Alfred Schutz relacionadas a formas de experienciar a realidade, seja no campo cotidiano, seja no científico. Identificamos nas concepções terraplanistas modos de caracterização da realidade que são típicos do campo cotidiano, mas acentuados e extrapolados para o contexto cientifico, em especial para avaliar o formato da Terra e seu movimento. Apresentamos, ainda, exemplos de ideias expressas por adeptos do terraplanismo que apontam para essa direção. Consideramos importante que professores de ciências se apropriem do fenômeno recente da crescente disseminação de movimentos negacionistas e anticientificos, buscando compreender suas características e discuti-las com estudantes, principalmente sob o ponto

\footnotetext{
${ }^{+}$Flat earthism and the appeal to personal experience as epistemological criterion

* Recebido: junho de 2020. Aceito: setembro de 2020.

${ }^{1}$ E-mail: fabio.marineli@ufla.br
} 
de vista epistemológico, esclarecendo seus critérios simplificadores e limitantes.

Palavras-chave: Movimentos Negacionistas; Terraplanismo; Crise Epistemológica; Experiência da Realidade.

\begin{abstract}
Negationist movements have been hitting the spotlight mainly disseminated through social media in the last years. A growing support to these ideas and to fake news can be traced back to an epistemological crisis related to the loss of trust toward socially foundational institutions, including science. Incredulous individuals increasingly depend on their own experiences and beliefs, a phenomenon which extends to areas such as the scientific domain. This paper addresses a dimension of the current flat earthism: the appeal to personal experience as indisputable epistemological criterion. Our approach is mainly supported by the discussions conducted by Alfred Schulz regarding the ways of experiencing reality, both in the everyday and in the scientific provinces. We were able to identify, in flat earthism, typically everyday characterizations of reality emphasized and extrapolated to the scientific context, particularly regarding their assessment on Earth's shape and rotation. Our analysis is enriched through real-world examples of flat earthist notions on these subjects. We consider that the appropriation, by science teachers, of the recent phenomena of growing dissemination of negationist and anti-science movements is essential in order to understand their characteristics and discuss then with students, especially from an epistemological point of view, clarifying their simplifying and limiting criteria.
\end{abstract}

Keywords: Negationist Movements; Flat Earthism; Epistemological Crisis; Experience of Reality.

\title{
I. Introdução
}

O documentário A Terra é Plana, ou Behind the Curve no original em inglês, dirigido por Daniel J. Clark, foi lançado em 2018 e atualmente encontra-se disponível na Netflix². A

\footnotetext{
${ }^{2}$ A Netflix é uma provedora de filmes e séries de televisão via streaming, sediada nos Estados Unidos, mas que atual mundialmente.
} 
obra busca compreender quem são e como pensam aqueles que acreditam no terraplanismo, apresentando um retrato de como essas pessoas divulgam suas ideias utilizando mídias sociais, das relações que estabelecem por meio de convenções, da crença em teorias conspiratórias, da imagem que possuem da ciência, das tentativa frustradas de realização de experimentos que confirmem suas concepções e, de maneira menos explícita, dos critérios que utilizam para caracterizar como verdadeira a planicidade da Terra.

A existência desse documentário, que apresenta um tom crítico ao movimento retratado, é um exemplo da crescente visibilidade que ideias negacionistas vêm ganhando atualmente. Eventos históricos, como o holocausto ou a ditadura militar no Brasil, muitas vezes são negados ou relativizados, assim como o aquecimento global, a função das vacinas e até a esfericidade da Terra. Ideias como essas encontram hoje em dia campo fértil na internet e nas mídias sociais, que levam esse tipo de conteúdo a grandes audiências.

Dados do relatório 2019 Digital Global (HOOTSUITE; WE ARE SOCIAL, 2019a, 2019b) apontam para a massiva utilização da internet em todo o mundo, inclusive no Brasil. Nesse último, no ano de 2019, 70\% da população fez uso da internet, mais de 149 milhões de pessoas, com $85 \%$ delas acessando todos os dias. Do total de utilizadores, 140 milhões usavam mídias sociais ( $66 \%$ da população), sendo que 130 milhões por meio de dispositivos móveis. Mais impressionante que esses números é o tempo médio que os brasileiros passaram por dia na internet em 2019: nove horas e vinte nove minutos, com três horas e trinta e quatro minutos em mídias sociais. Ainda de acordo com o relatório citado, 100\% dos usuários de internet no Brasil utilizavam redes sociais ou serviços de mensagens e $98 \%$ deles assistiam vídeos online.

A presença da internet na vida das pessoas trouxe ganhos expressivos quando consideramos a facilidade de obtenção de conhecimentos sobre os mais diversos assuntos. Até as fontes de informação tradicionalmente publicadas em formato impresso agora encontramse disponíveis na rede em formato eletrônico. No entanto, não é possível fechar os olhos para a imensa quantidade de equívocos e desinformação que nela circulam.

Alguns movimentos negacionistas já existiam bem antes da ampla utilização da internet dar força a eles. Como exemplo, Albuquerque e Quinan (2019) mencionam a International Flat Earth Society, fundada no ano de 1956. Contudo, as oportunidades tecnológicas dadas pelas mídias sociais ofereceram novo impulso a algumas dessas ideias e propiciaram a disseminação de outras. Para mencionar nosso país, em um levantamento realizado pelo Instituto Datafolha em 2019 foi constatado que aproximadamente 11 milhões de brasileiros acreditavam que a Terra é plana (GARCIA, 2019). Algo mais frequente entre os menos escolarizados.

Nos últimos anos, expressões como pós-verdade e fake news ganharam notoriedade. O dicionário Oxford escolheu a expressão pós-verdade como palavra do ano em 2016. De acordo com o dicionário, "pós-verdade é um adjetivo definido como algo 'relacionado ou que denota circunstâncias nas quais fatos objetivos têm menos influência em moldar a opinião 
pública do que apelos a emoções e a crenças pessoais"” (OXFORD DICTIONARY, 2016, tradução nossa). Já fake news seriam "informações noticiosas que buscam alertar o público para alguma situação ou retratar um ponto de vista de um acontecimento. Entretanto [...] possui parte ou todo seu conteúdo composto de informações inverídicas" (PAULA; SILVA; BLANCO, 2018). As fake news e as estratégias de desinformação muitas vezes são utilizadas de forma deliberada, existindo, até, produtores de notícias falsas, especialistas no disparo de mensagens que visam causar dúvidas e confusões para influenciar eleições (CAVALCANTI, 2018). Além das consequências desastrosas na esfera política, que sofreu enormes influências de conteúdos desinformativos nas últimas eleições, inclusive no Brasil (INTERVOZES, 2019; MICHALSKI; PAULA, 2019), as notícias falsas também podem influenciar negativamente outras áreas, igualmente com consequências nefastas, como boatos que afirmam que vacinas fazem mal (BEDFORD, 2019; AQUINO, 2019) ou os mais recentes relacionados à Covid-19 (FIOCRUZ, 2020).

A reação a sites especializados em espalhar desinformação também vêm crescendo. Um exemplo é o movimento Sleeping Giants, composto por ativistas que buscam persuadir empresas a não realizarem propagandas em sites que espalham fake news e discursos de ódio. Teve início em 2016 nos Estados Unidos e em 2020 começou suas atividades no Brasil. Vêm obtendo relativo sucesso em cortar as fontes de financiamento desses sites. Outro exemplo são as iniciativas do Tribunal Superior Eleitoral para o enfrentamento à desinformação 3 .

A disseminação e acolhida de notícias falas, assim como de ideias negacionistas e conspiratórias, podem ser apontadas como indício de uma crise epistemológica, que, conforme indicam Albuquerque e Quinan (2019, p. 84), "se traduz na perda de confiança em instituições fundamentais da sociedade, dentre as quais a própria universidade". Ainda de acordo com esses autores, isso representa um desafio inédito à sociedade contemporânea, que vem sendo influenciada por esses movimentos.

A perda de confiança nas instituições, somada à possibilidade de acesso pessoal e direto a informações sem intermediários, por meio de mídias sociais, smartphones etc., acaba dando força ao fenômeno da pós-verdade. Muitas vezes os indivíduos descartam uma ideia ou informação, ou simplesmente consideram-nas falsas, pelo mero motivo de serem contrárias às suas crenças pessoais.

Quando a dúvida sistemática recai sobre as instituições, quando se duvida da imprensa, da ciência, da política, as pessoas se tornam cada vez mais dependentes das próprias experiências e crenças sobre como o mundo funciona. Surge aqui a crise: "os indivíduos suspeitam cada vez mais das histórias 'oficiais' que estão sendo contadas e esperam testemunhar as coisas por si mesmos” (DAVIES, 2019, tradução nossa).

Concordando com Davies (2019), claro que certo nível de crítica em relação às instituições é bem-vindo, o que leva a uma menor possibilidade de manipulação das pessoas.

\footnotetext{
${ }^{3}$ Disponível em: <http://www.justicaeleitoral.jus.br/desinformacao>. Acesso em: 14 jun. 2020.
} 
Não dá para negar que a opressão a certos grupos é algo entranhando em nossa sociedade e muitas vezes meios oficiais serviram e servem como veículos de ideias de dominação. No entanto, o que se vê hoje em dia não é uma postura crítica, mas algo que vai além, uma postura negacionista, baseada em critérios bastante questionáveis.

A enxurrada de informações, notícias e conteúdos que se têm acesso, diversas vezes contrários entre si, obriga os indivíduos a fazer seleções e escolhas pessoais, sem auxílio de intermediários. No lugar do acesso a apenas eventos importantes, escolhidos e veiculados por canais tradicionais de mídia, hoje tudo pode ser registrado e divulgado pela internet. Surge daí a noção de que os dados "podem falar por si", representando "uma verdade mais pura do que a apresentada por editores profissionais ou especialistas" (DAVIES, 2019, tradução nossa). Desse modo, o acesso à "verdade" estaria garantido.

A importância das questões individuais acaba ganhando contornos ainda mais proeminentes com as mídias sociais, onde o importante é expressar a si mesmo, seu mundo privado e pessoal. Nas mídias sociais as experiências pessoais ficam no topo da credibilidade da hierarquia das informações (ALBUQUERQUE; QUINAN, 2019).

Talvez pudéssemos compreender esse processo como uma espécie de empirismo pessoal limitante. Ele aparece como algo mais restrito que o empirismo clássico - em que é possível falar de maneira geral sobre o conhecimento derivar da experiência -, já que, aqui, apenas as experiências pessoais, adquiridas individualmente, importam. E de uma maneira que limita certos entendimentos, já que são interpretadas com esquemas de referência do cotidiano, conforme trataremos adiante.

O fenômeno do crescimento dos movimentos negacionistas e anticientíficos, como o da Terra plana, é multifacetado e complexo. A internet e as redes sociais tornaram-se elementos essenciais desse fenômeno, já que congregam e dão voz a indivíduos que anteriormente estavam restritos a falar para pequenas audiências. Esses movimentos possuem diversas características - como a crença de seus defensores em teorias da conspiração, em fake news, entre outros -, mas neste trabalho vamos nos ater a uma em específico: a primazia do pessoal como critério de atribuição de verdade. Não é nossa intenção querer simplificar um fenômeno que é complexo, mas consideramos que essa característica merece algumas considerações, o que contribuirá para o esclarecimento de critérios epistemológicos simplificadores e limitantes dos movimentos negacionistas, em especial do terraplanismo. Isso pode inclusive auxiliar em discussões sobre esses movimentos em atividades de ensino, nas quais esses critérios poderiam ser examinados, discutidos e até confrontados.

Buscaremos, a seguir, mencionar porque certas noções que apelam de maneira simplificada para experiências diretas, baseadas nos sentidos, parecem atraentes para as pessoas no geral. Para tanto, exploraremos algumas ideias de Alfred Schutz (1962) e de Peter Berger e Thomas Luckmann (2005) acerca de uma análise fenomenológica das maneiras pelas quais entendemos e nos relacionamos com a realidade do dia a dia e como isso possui diferenças com o campo da ciência, especificamente das teorizações científicas. 


\section{Abordagens fenomenológicas sobre a experiência da realidade}

No texto On Multiple Realities, Schutz (1962) faz uma descrição fenomenológica da experiência de realidade na vida cotidiana, ou seja, aquela em que todos estamos imersos no dia a dia. Berger e Luckmann (2005), baseados em parte nas colocações de Schutz, tecem considerações sociológicas acerca dessa realidade.

O mundo cotidiano é geralmente tratado como sendo "a" realidade (BERGER; LUCKMANN, 2005), chamado por Schutz de "realidade primordial"4. A sua estabilidade dinâmica (permanência na mutabilidade) lhe confere existência própria, autonomia e constância, o que faz com que a realidade do dia a dia seja considerada como imutável e permanente. Pessoas que vivem em uma mesma sociedade tendem a perceber essa realidade de maneira semelhante e pouco refletem sobre seus fundamentos, tratando-a como algo natural (SCHUTZ, 1962), uma vez que são motivos pragmáticos que governam as pessoas no mundo da vida diária. Além disso, a realidade da vida cotidiana é, em certo sentido, intersubjetiva, tão real para mim quanto para os outros; muitas das minhas percepções sobre as coisas e as percepções dos outros parecem corresponder neste mundo que partilhamos. Por ser partilhada, além dos fenômenos parecerem independentes da apreensão que temos deles, essa realidade cotidiana é mais facilmente admitida como "a" realidade. Ela está aí, evidente por si mesma e compulsória, dada à nossa experiência e interpretação.

Por tudo isso, podemos pensar que as concepções advindas do cotidiano são altamente "enraizadas", ainda mais considerando que vão se formando desde a infância, quando estamos nos desenvolvendo em meio a um mundo já formado e estabelecido. Segundo Schutz, parte das nossas interpretações sobre o mundo nos é dada pelas experiências e interpretações de outros, que nos antecederam nele, e as adquirimos por meio de interações sociais. Isso funciona como um esquema de referência, que atribui sentido às coisas, indicando que o mundo em que vivemos é um mundo de objetos bem circunscritos, com qualidades definidas, entre os quais nos movemos e sobre os quais podemos atuar. Schutz afirma ainda que dentro do esquema de referência do cotidiano não há interesse nem razão em se levantar dúvidas em relação aos objetos, na medida em que esse esquema funciona satisfatoriamente. Não há razão para duvidar que nossas experiências nos oferecem um acesso às coisas como realmente são nesse mundo que é ao mesmo tempo cenário e objeto de nossas ações e interações. Esse é um ponto importante para as nossas discussões que apresentaremos adiante.

Uma descrição das características do estilo cognitivo da realidade cotidiana foi feita por Schutz (1962) com os seguintes apontamentos: as pessoas mantêm-se nela com uma atitude alerta, que se origina de uma plena atenção à vida ${ }^{5}$ há uma atitude específica de

\footnotetext{
${ }^{4}$ Paramount reality, no original.

5 Essa atenção seria uma atenção ativa, dirigida a pôr em prática um projeto, executar um plano. Isso daria significatividade pragmática a certos setores do mundo, o que determinaria nossa corrente de pensamento.
} 
suspensão da dúvida em relação aos objetos à volta, ou seja, coloca-se "entre parêntesis" a dúvida de que o mundo e seus objetos possam ser diferentes do que parecem ser (Schutz denomina isso de epoché da atitude natural6); há uma forma predominante de espontaneidade, com ações baseadas num projeto e caracterizadas pela intenção de produzir o estado de coisas projetado, através de movimentos do corpo no mundo exterior; há uma forma específica de experimentar o próprio "si mesmo" (o si mesmo "executante" como um si mesmo total); há uma forma específica de sociabilidade (um mundo intersubjetivo comum, da comunicação e da ação social); há uma perspectiva temporal específica ${ }^{7}$.

No entanto, a concepção cotidiana sobre o mundo não é única; em um mesmo contexto social podemos ter diferentes formulações do que seja a realidade. Suas formulações teóricas - quer sejam científicas, filosóficas, mitológicas etc. - podem caracterizar a realidade em diferentes termos. E não esgotam o que é "real" para os membros de uma sociedade.

Nesse sentido as "diferentes realidades" podem ser consideradas como campos finitos de significado $^{8}$, com formas de significar o mundo e modos de experiência delimitados. Isso até mesmo para a realidade cotidiana, que é considerada como "primordial" por estarmos inseridos nela de forma compulsória e não podermos nos desvencilhar dela durante nossa vida. E mesmo após nos "deslocarmos" para outro campo de realidade, sempre acabaremos voltando à realidade do dia a dia.

Segundo Schutz (1962), esses campos finitos de significado são determinados por um conjunto de experiências, relacionadas a um estilo cognitivo específico, que são - em relação a esse estilo - coerentes e compatíveis umas com as outras. Ou seja, cada um desses campos possui características internas específicas. No entanto, as características deles não são necessariamente compatíveis com as da vida cotidiana. Enquanto nessa última há uma atitude específica de suspensão da dúvida em relação aos objetos poderem ser diferentes do que parecem ser, e ao acesso a eles por meio dos sentidos, em outros campos essa suspensão pode não existir e os objetos ou a percepção deles serem colocados em dúvida ou, então, tratados

\footnotetext{
6 Ainda sobre a epoché da atitude natural, Schutz esclarece: "A fenomenologia nos ensinou o conceito de epoché fenomenológica, a suspensão de nossa crença na realidade do mundo como um dispositivo para superar a atitude natural, radicalizando o método cartesiano da dúvida filosófica. Pode-se sugerir que o homem dentro da atitude natural também usa uma epoché específica, é claro, mas bastante diferente daquela que emprega o fenomenólogo. Ele não suspende a crença no mundo exterior e seus objetos, mas, ao contrário, ele suspende a dúvida em sua existência. O que ele coloca entre parênteses é a dúvida de que o mundo e seus objetos podem ser diferentes do que lhe parecem. Propomos chamar essa epoché de epoché da atitude natural" (SCHUTZ, 1962, p. 229, tradução nossa).

${ }^{7}$ Schutz chama essa perspectiva de tempo padrão, que seria uma interseção do "tempo interior" e do "tempo cósmico", como estrutura de tempo universal do mundo intersubjetivo. O "tempo interior" seria aquele dentro do qual nossas experiências atuais se conectam com o passado, mediante recordações e retenções, e com o futuro, mediante projeções e previsões. Já o "tempo cósmico" seria aquele que pode ser medido com cronômetros, baseado nas sequências temporais da natureza (SCHUTZ, 1962).

${ }^{8}$ Nos originais em inglês das obras de Schutz e de Berger e Luckmann a expressão que aparece é finite provinces of meaning.
} 
de forma diferente daquela do dia a dia, não mais como realidade dada. O que ocorre no campo da ciência, por exemplo.

Para Schutz (1962) os diferentes campos são finitos, o que implica que não haveria possibilidade de se fazer uma completa correlação de elementos entre eles introduzindo uma fórmula de transformação. A mudança se daria somente por meio de uma "comoção", que seria uma forma diferente de tensão da consciência, baseada em uma diferente atenção à vida. Nesse mesmo sentido, Berger e Luckmann (2005) colocam que a própria linguagem que usamos é fundada na realidade do dia a dia e quando ela é utilizada para interpretar outros campos, eles são distorcidos por essa tentativa de "tradução". Isso pode ser visto na tentativa de se relatar mundos de significação teóricos na ciência, estéticos ou religiosos. "O físico teórico diz-nos que seu conceito de espaço não pode ser transmitido por meios linguísticos, tal como o artista em relação ao significado de suas criações e o místico com relação a seus encontros com a divindade" (BERGER; LUCKMANN, 2005, p. 44).

No entanto, Berger e Luckmann também indicam que essa espécie de "tradução" seria uma forma de relacionar diferentes campos, o que entendemos ser uma concepção diferente da que foi colocada por Schutz, que os considera completamente separados. Para Berger e Luckmann, a linguagem ordinária pode se referir a elementos de outros campos finitos de significado e, com isso, certas acepções desses campos seriam integradas no campo da vida cotidiana, o que seria uma espécie de transposição de elementos das distintas realidades, formando um enclave dentro da realidade do dia a dia. Entretanto, esses elementos do outro campo ficariam dotados de sentido em termos da realidade da vida cotidiana em vez de serem entendidos nos termos da sua própria realidade particular. Esses enclaves produzidos por esse tipo de transposição pertenceriam, de certa forma, a ambas as esferas de realidade, estando localizados em uma delas, mas se referindo a outra.

Elementos que, desse modo, abrangem diferentes campos de realidade podem ser caracterizados como símbolos e a linguagem usada para se referir ao que está em outra realidade seria uma linguagem simbólica, o que permitiria serem feitas referências a regiões inacessíveis à experiência ordinária. A religião, a filosofia, a arte e a ciência, com seus sistemas próprios de símbolos, se enquadram aqui. E esses sistemas de símbolos, apesar de altamente abstraídos das experiências diárias, são elementos reais na vida do dia a dia.

Para Schutz, cada campo finito de significado possui uma forma própria de atenção à vida, uma maneira peculiar de epoché ou de suspensão da dúvida, uma forma predominante de espontaneidade, uma forma específica de experiência de si mesmo e de sociabilidade, bem como uma perspectiva temporal própria. Mas, mesmo assim, o mundo cotidiano permaneceria como um "arquétipo" de nossa experiência de realidade e os demais âmbitos poderiam ser considerados como suas modificações.

Nos termos postos, a teorização científica se configura como um campo finito de significado, diferente do campo cotidiano. Enquanto no pensamento cotidiano há uma suspensão da dúvida em relação aos objetos percebidos à volta, no campo da teorização há 
uma suspensão da subjetividade do pensador ${ }^{9}$, incluindo sua existência corporal (a existência física do cientista é posta "entre parêntesis" e em tese seu ponto de vista subjetivo e problemas pessoais são "suspensos" frente a problemas e soluções que devem ter caráter mais geral); há, ainda, a suspensão do sistema de orientação pelo qual o mundo da vida cotidiana é agrupado em zonas, que se referem àquilo que está ao alcance ou não (podendo, na ciência, ser feita referência a realidades distantes, como no caso daquilo que é microscópico ou está localizado onde nenhuma pessoa tem acesso); há a suspensão do sistema de significações pragmáticas (o pensamento teórico pode ser revisto, alterado ou desfeito sem provocar nenhuma mudança no mundo externo). As significações na ciência passam a ser estabelecidas por meio do problema que está sob investigação, ou seja, é a questão em análise que determina como significativos os elementos do mundo que estão ou podem estar relacionados a ela, além de demarcar quais pontos são de interesse para se deter e investigar.

As cogitações teóricas, como os modelos físicos sobre o mundo, por exemplo, não são atos operativos. Já ações como medir, manejar instrumentos, executar experimentos etc., assim como escrever artigos, realizar conferências entre outros são condições ou consequências de teorizações, mas, segundo Schutz, não pertencem à atitude teórica mesma.

As distinções postas por Schutz entre o campo cotidiano e o da teorização científica, dizem respeito sobretudo a diferentes tensões na consciência quando alguém trata ou está imerso nas questões desses mundos. Nesse sentido, parece ser razoável considerar a existência de diferenças entre eles. No entanto, temos de levar em conta que existem outras abordagens sobre o mundo que não são essas duas, algo talvez intermediário a elas, como conhecimentos científicos aplicados a situações concretas, conhecimentos tecnológicos etc., que não permitiriam essa distinção tão clara, ou mesmo se aproximariam mais das características cotidianas. Por isso, inclusive, que Berger e Luckmann estabelecem a noção de "enclaves de realidade", quando um desses universos estaria dentro do outro ou em relação com o outro.

Apesar de não ser o foco das análises de Schutz, podemos também fazer distinções epistemológicas em relação ao olhar cotidiano e à concepção da ciência sobre o mundo. Nesse ponto, não estaríamos tão somente tratando de formas de experienciar esses diferentes universos, mas tratando de distinções deles próprios. Falando de forma geral, é possível apontar como característica das ciências físicas a necessidade de coerência e compatibilidade com outras proposições científicas, que as suas explicações sejam desenvolvidas buscando generalidade e utilizem como parâmetro a confrontação experimental, além de a ciência estar

\footnotetext{
${ }^{9}$ Há aqui uma concessão a ser feita em relação à suspensão da subjetividade do cientista, que diz respeito à definição de seu campo de estudo. Nesse caso pode haver elementos subjetivos envolvidos, já que características pessoais podem ser determinantes na escolha da sua área de atuação ou mesmo na escolha de questões que estuda. No entanto, após essas escolhas, ele entra em um universo da tradição histórica da sua área, que abarca os resultados obtidos por outros cientistas, com problemas enunciados por outros, soluções sugeridas por outros e métodos elaborados também por outros (SCHUTZ, 1962). Ou seja, adentra um campo finito, com seu estilo peculiar, e os problemas que surgem no âmbito científico devem participar do estilo universal desse campo e ser compatível com outros problemas tratados nele, bem como com as soluções aceitas. Dessa forma, a liberdade individual que goza o cientista é limitada.
} 
em constante busca pelo aperfeiçoamento e pela ampliação do conhecimento (CHALMERS, 1994), especificidades essas que não estão presentes nos conhecimentos do cotidiano. Nesse sentido, o conhecimento científico é diferente daquele do dia a dia, já que é resultado de um processo de interpretação do mundo baseado em técnicas e métodos que se diferenciam das formas empregadas cotidianamente, gerando uma forma de conceber o mundo que não é a mesma do senso comum.

\section{Ainda caracterizações do mundo pela ciência e da perspectiva do campo cotidiano}

Um aspecto importante da ciência, entre outras coisas, é que ela permite que uma compreensão do mundo sob um ponto de vista diferente das formas de conhecimento que em geral vêm do mundo cotidiano. Ela possui uma racionalidade específica, além de critérios epistemológicos próprios de caracterização do mundo.

Nesse sentido, Martins, Ogborn e Kress (1999, p. 30) afirmam que aprender ciência envolveria "[...] passar a conceber o mundo físico de forma diferente e vislumbrar outras dimensões da relação entre o homem e a natureza". Como exemplo dessa forma diferente de conceber o mundo, esses autores afirmam que, na concepção científica, a matéria passa a ser vista como composta, principalmente, por espaço vazio; germes microscópicos, e não a chuva ou o vento frio, passam a ser a causa dos resfriados; a Terra, normalmente vista como o chão em relação ao qual nos movimentamos, passa a ser considerada como ativa e em constante movimento. Como destaca Tiercelin (1999), quanto mais a ciência progride, mais parece divergir da descrição que o senso comum atribui ao mundo. $E$ isso pode gerar questionamentos em relação ao conhecimento produzido por ela. Matthews (1994), falando sobre a utilização de idealizações pela ciência, coloca que essas idealizações são um dos maiores obstáculos à aprendizagem científica, em parte porque as crenças intuitivas são fortemente influenciadas pela experiência concreta do dia a dia. Isso aponta novamente para a ideia de que os conhecimentos científicos e as conceituações vindas do cotidiano caracterizam o mundo de formas distintas.

Em relação à caracterização do mundo feita pela ciência, que inclusive utiliza entidades não diretamente acessíveis aos sentidos, cabe aqui indicar uma ideia posta por Gupta, Hammer e Redish (2010), que afirmam que nossos órgãos dos sentidos, bem como as ferramentas que nosso cérebro possui para interpretar os dados que chegam desses órgãos, são evolutivamente otimizados para lidar com as experiências cotidianas. Nossos olhos, por exemplo, detectam uma gama limitada do espectro eletromagnético, na região em que se encontra a maior parte da radiação solar, e os objetos que precisamos lidar no dia a dia refletem bem essas frequências, são visíveis nelas - o que precisamos encontrar para nos sustentar ou mesmo o que precisamos evitar para garantir a passagem de nossos genes a uma nova geração. Como sabemos, isso não significa que não haja informações em outras faixas de frequência, inclusive alguns animais são sensíveis à luz nessas outras faixas. De maneira semelhante, as categorias que nosso cérebro utiliza para lidar com nossa sobrevivência 
também são boas o suficiente para a experiência cotidiana. No entanto, para esses autores, a atividade científica busca um entendimento mais profundo e analítico. Assim como os instrumentos científicos podem ir além das limitações dos nossos órgãos sensoriais, mostrando outros aspectos da realidade, as teorias científicas podem ir além das limitações das nossas compreensões diretas sobre o mundo, criando categorias mais complexas e sutis.

Temos, pois, que entre o conhecimento científico e as caracterizações baseadas no senso comum, além de representarem diferentes formas de experienciar a realidade, existem distinções que são epistemológicas. As formas de construção do conhecimento, ou as maneiras de se caracterizar algo como "verdadeiro", podem variar conforme estamos no universo da ciência ou naquele do dia-a-dia.

Compreender o mundo do ponto de vista científico implica em uma mudança nas nossas categorias epistemológicas advindas do senso comum. A atitude de suspensão da dúvida de que os objetos e circunstâncias possam ser diferentes do que parecem ser, apontada por Schutz como parte do estilo cognitivo do campo cotidiano, precisa ser relativizada, o que de certo modo é contraintuitivo. Dentro do universo científico, a utilização da própria experiência e dos sentidos sob a perspectiva dos esquemas de referência da realidade cotidiana não necessariamente funciona como critério confiável de caracterização da realidade.

\section{Apelo aos sentidos e à experiência pessoal como critério epistemológico incontestável}

Certas propriedades das nossas vivências do dia-a-dia são acentuadas naquilo que chamamos anteriormente de empirismo pessoal limitante, que aceita apenas as próprias experiências como critério epistemológico, interpretadas com os esquemas de referência do campo cotidiano. Isso está relacionado à crise epistemológica do tempo presente (ALBUQUERQUE; QUINAN, 2019), caracterizada pela perda de confiança nas instituições, inclusive na ciência, o que traz para os indivíduos, descrentes nessas instituições, a necessidade de definição de critérios para caracterizar a realidade. Quando tudo é desacreditado, uma saída é acreditar em si mesmo, naquilo que é percebido diretamente por si, até para avaliar o que se encontra no campo científico.

Esse é um fenômeno que pode ser observado em membros de movimentos como o terraplanismo, que elegem as experiências pessoais e as evidências dos sentidos (ou a falta delas) como critério para defender suas concepções acerca da Terra plana.

Apresentaremos a seguir alguns exemplos de ideias evidenciadas por terraplanistas, que apontam para essa direção, sem termos a pretensão de sermos exaustivos ou de realizarmos uma análise sistemática delas.

O documentário citado no início do presente trabalho, intitulado A Terra é Plana, possui como protagonista Mark Sargent, um dos líderes do movimento terraplanista nos EUA. Logo no início da produção, aproximadamente aos quatro minutos, ele aparece segurando uma pequena esfera pintada como se fosse nosso planeta, dizendo: 
Como [você] sabe que [a Terra] é um globo? Porque viu isso [se referindo à esfera em sua mão]. Não foi lá em cima em um carro voador. Não tem uma nave espacial ${ }^{10}$.

Vemos nessa fala um apelo aos sentidos e à necessidade de se testemunhar as coisas por si mesmo. Segundo o argumento apresentado, a crença na esfericidade da Terra estaria relacionada ao contato com modelos que a representam de forma esférica, uma vez que nós mesmos não fomos "lá em cima" ver como ela realmente é. Na concepção do protagonista, se fôssemos, poderíamos ver que a Terra é plana.

Essa questão dos sentidos aparece novamente, aproximadamente aos seis minutos do documentário, quando Mark afirma que

O motivo de estarmos vencendo contra a ciência, é porque [os cientistas] só falam em matemática. E nós dizemos: 'Ei, ali é Seattle'. Pode ver através de sua câmera. É isso, uma imagem vale mais que mil palavras.

A questão de ver Seattle diz respeito ao fato de Mark e seus interlocutores naquele momento estarem em uma ilha, a certa distância da cidade de Seattle - que fica no continente - e conseguirem ver alguns de seus prédios, após um trecho de mar. Para Mark, isso não seria possível se a Terra fosse curva. Aparece aqui uma comparação entre um acesso direto ao mundo, pelos sentidos, em contraponto à ciência que, segundo o protagonista, só fala em matemática. Não vamos entrar na questão da distância entre o observador e os prédios, que mostraria que não há contradição entre a Terra ser esférica e a possibilidade de enxergar algo alto a longas distância, mas apenas chamar a atenção para o raciocínio utilizado.

A menção à ciência indica haver uma disputa com ela - que Mark diz estar vencendo - justamente sobre a adoção dos sentidos e das experiências pessoais como critério epistemológico. No campo científico, os objetos e as percepções sobre eles muitas vezes são colocados em dúvida, ganhando relevo outras maneiras de construir conhecimento sobre o mundo, inclusive utilizando a matemática, o que parece ser um problema para o protagonista em questão.

No geral, vemos que Mark, em suas falas, utiliza a ideia da necessidade de se perceber algo diretamente, por si, como critério tanto para negar a esfericidade da Terra (você não foi lá em cima em um carro voador e viu isso), quanto para afirmar sua planicidade (vemos prédios distantes, o que não seria possível se ela fosse esférica). Esses exemplos indicam aquilo que Schutz chamou de epoché da atitude natural, ou seja, a suspensão da dúvida em relação ao mundo ser diferente do que parece ser. Essa característica típica das formas cotidianas de pensar é um elemento central das argumentações do protagonista do documentário.

\footnotetext{
${ }^{10}$ Esse trecho está traduzido do idioma original, conforme parece na legenda do próprio documentário. As partes entre colchetes são acréscimos nossos, para auxiliar no entendimento do trecho.
} 
Mas Mark não é o único que aparece na produção utilizando a experiência pessoal e os sentidos dessa maneira. Um pouco antes dos vinte e nove minutos, um entrevistado, chamado Nathan Thompson, afirma:

É loucura o que ensinam. Eu não sinto o movimento [da Terra] e eles acham que nos movemos mais rápido do que uma bala?

Aqui, a falta sensação de movimento é utilizada para considerar que a Terra está parada. O que vai ao encontro daquilo que foi dito por Mark e de sua forma de pensar, que leva em consideração que os esquemas de referência do cotidiano (SCHUTZ, 1962) são bons o suficiente para avaliar o movimento da Terra.

Outra figura de destaque no documentário, que muitas vezes aparece ao lado de Mark Sargent, é Patrícia Steere, que mantém um podcast ${ }^{11}$ com o tema da Terra plana. Um pouco antes dos trinta e nove minutos, durante uma entrevista, perguntam-lhe: "em que fontes você confia?". No que ela responde:

Em mim mesma. Só. Eu digo de brincadeira que se houvesse um evento como, digamos, o atentado de Boston. Não vou acreditar que esses eventos sejam reais a não ser que minha perna exploda.

A fala dela é um exemplo claro da primazia do pessoal, da necessidade do testemunho particular para a crença em alguma coisa. Para ela, sem a experiência própria não seria possível haver confiança em algo.

Esses exemplos retirados do documentário têm em comum a ideia de que a experiência pessoal e os dados dos sentidos, interpretados com os parâmetros do campo do dia a dia, são critérios epistemológicos indubitáveis de caracterização do mundo. Não há questionamento em relação a eles. Para os terraplanistas, se a Terra é sentida como estando parada, ela realmente está parada; se é vista como plana, ela realmente é plana, o que se enquadra na epoché da atitude natural.

Mas não é só nesse documentário que podemos identificar esse tipo de concepção. No YouTube ${ }^{12}$, por exemplo, existem diversos canais especializados em tratar do tema da Terra plana, dentre eles o denominado "Professor Terra Plana", que desde 2017 vem postando vídeos defendendo o terraplanismo ${ }^{13}$. Para se ter uma ideia de seu alcance, no dia 11 de junho de 2020, os vídeos do canal somavam mais de um milhão e setecentas mil visualizações.

\footnotetext{
11 Podcast é uma mídia de transmissão de informações de áudio pela internet, que pode ser ouvida sob demanda.

12 Plataforma de hospedagem e compartilhamento de vídeos na internet. Disponível em: $<$ https://www.youtube.com>.

${ }^{13}$ Uma análise de aspectos desse canal pode ser encontrada em Albuquerque e Quinan (2019).
} 
Entre seus vídeos, há um postado em 5 de julho de 2018, “As 35 perguntas frequentes sobre a Terra plana respondidas"14, com cerca de 280 mil visualizações. Nele são apresentadas respostas a um conjunto de perguntas, elucidando o pensamento terraplanista sobre elas. Ao longo dessas respostas, aparecem inúmeras alegações falsas ou sem qualquer respaldo, assim como o apelo a conspirações mundiais como explicação para a visão corrente da Terra como um globo. Além dessas questões, podemos ainda identificar diversas vezes no vídeo o recurso à utilização dos sentidos e da experiência pessoal como critério epistemológico para caracterizar a Terra como sendo plana. Vamos indicar algumas.

A resposta à pergunta “A terra plana se move?", que para eles é negativa, é justificada aos oito minutos e três segundos do vídeo nos seguintes termos:

[...] a pseudociência [referindo-se à ciência] diz que a Terra está girando a 1000 milhas por hora, enquanto avançando a 67 mil milhas por hora em torno do Sol, se atirando pelo sistema solar a 500 mil milhas por hora através da Via Láctea, enquanto viaja a 670 milhões de milhas por hora através do espaço sideral. Contudo todos sabem que nós não sentimos nada disso.

Nesse trecho utiliza-se a ausência de sensação do movimento da Terra para justificar que ele não existe, ou seja, para defender uma Terra parada e, consequentemente, que a ciência está errada. Cabe mencionar que a Terra estar imóvel faz parte do modelo defendido no vídeo.

$\mathrm{Na}$ resposta a uma pergunta sobre satélites e a Estação Espacial Internacional (International Space Station no inglês, ou ISS), é afirmado que os satélites espaciais não existem e que as imagens deles seriam falsas. Aos nove minutos e quinze segundos, é dito:

Apenas pense sobre isso: se realmente existem mais de 10 mil satélites em órbita da Terra, como nos dizem, então por que não podemos ver sequer algum passar na frente da Lua ou nas imagens da ISS?

O padrão se repete: o fato de não vermos a olho nu satélites artificiais passando em frente à Lua, por exemplo, é usado como argumento para negar que haja satélites em órbita. É possível sim ver satélites no céu, mas isso não é comentado no vídeo, ainda mais por ser dito, em outro momento, que ninguém sabe ao certo o que são as luzes vistas no céu, incluindo-se aí as estrelas.

Finalmente, um último trecho que destacamos é a resposta a uma questão sobre porque o Sol e a Lua parecerem ser do mesmo tamanho. Aos quinze minutos e quarenta e dois segundos do vídeo é dito:

\footnotetext{
14 Disponível em: <https://www.youtube.com/watch?v=IkcDpotI41Q >. Acesso em: 11 jun. 2020.
} 
O Sol e a Lua parecem ser do mesmo tamanho e é exatamente porque eles de fato são mesmo. A pseudociência [referindo-se à ciência] quer que acreditemos que a razão pela qual vemos o Sol e a Luz do mesmo tamanho é devido à suposição de que o Sol seja 400 vezes maior que a Lua e esteja 400 vezes mais distante. Eles dizem que o que afirma a nós é apenas uma coincidência, mas essa é a forma deles tentarem explicar o porquê os dois empiricamente parecem ter o mesmo tamanho. É bastante óbvio que o Sol e a Lua estão circulando sobre carga e ambos são igualmente equilibrados, opostos e são do mesmo tamanho.

Nesse conjunto de trechos extraídos do vídeo do canal "Professor Terra Plana" evidencia-se um padrão, em que as sensações e a visão são utilizadas como critérios para determinar a ausência de movimento da Terra, a não existência de satélites artificiais em órbita de nosso planeta e o tamanho dos corpos celestes. Isso representa mais exemplos da epoché da atitude natural, da suspensão da dúvida de que os objetos poderiam ser distintos daquilo que aparentam ser, algo que faz parte do estilo cognitivo do campo da realidade cotidiana.

O conhecimento científico, inclusive as ideias sobre a Terra, vai além das limitações dos nossos órgãos dos sentidos e além, ainda, das nossas compreensões diretas sobre o mundo. Há, nos termos postos por Schutz, uma suspensão da subjetividade do pensador, enquanto ganha relevância soluções mais gerais, válidas de maneira mais ampla. Como foi dito, o primado dos sentidos e do pessoal é algo típico das formas cotidianas de experienciar a realidade. No entanto, nos trechos em questão aparece uma extrapolação desses critérios para aquilo que está fora do âmbito cotidiano, utilizando-os no campo científico, em especial para avaliar o formato da Terra e seu movimento.

Para finalizar esta seção, consideramos que cabem alguns apontamentos que julgamos corresponder a caminhos a serem tomados por propostas didáticas que visam lidar com a noção equivocada de que é no domínio das experiências pessoais que se deve avaliar epistemologicamente conhecimentos científicos. A ideia da utilização dos sentidos de maneira geral e irrestrita é atrativa, pois tem relação com o estilo cognitivo da realidade cotidiana, caracterizada por Schutz como "primordial". No entanto, extrapolar os critérios do campo cotidiano para aquele da ciência leva a enganos. O processo de compreender o mundo na perspectiva científica vai em outra direção, já que é um processo de questionamento e relativização dos critérios do dia a dia, da epoché da atitude natural, representando uma mudança nas categorias epistemológicas do senso comum.

Isso é algo que precisa ser construído e as aulas de ciências são um ambiente importante para tal construção. Aprender ciências vai além de um simples processo de incorporar conceitos e técnicas de resolução de problemas. Passa por adquirir uma compreensão do mundo sob pontos de vista diferentes daqueles que em geral possuímos, com maneiras de conhecer também diferentes. Nesse sentido, é importante o entendimento sobre 
como a ciência captura o mundo e a razão pela qual decidimos atribuir realidade a determinadas afirmações científicas (BARRA, 1998).

Consideramos que a construção desse entendimento sobre a ciência, e sobre as distinções entre seus critérios epistemológicos e aqueles do cotidiano, é algo que demanda a adoção de diferentes estratégias didáticas. Dentre elas, podemos mencionar a realização de atividades que buscam enfatizar o elevado poder explicativo e preditivo do conhecimento científico - que inclusive procura tratar do que se encontra longe dos sentidos, como aquilo que é muito pequeno ou que está muito longe, o que demanda a suspensão do sistema de orientação da realidade cotidiana acerca do que está ao alcance ou não. Outra possibilidade didática seria o desenvolvimento de estratégias que auxiliam a compreensão dos processos de construção do conhecimento pela ciência (o que também pode envolver aquilo que está longe dos sentidos), bem como de atividades em que os próprios estudantes se engajam nessa construção de maneira coletiva, como aquelas de modelização, por exemplo (PIETROCOLA, 1999; PINHEIRO; PIETROCOLA; PINHO-ALVES, 2005) - o que demanda certa suspensão da própria subjetividade, em prol do coletivo, bem como do sistema de significações pragmáticas, típico do cotidiano, já que o pensamento teórico pode ser revisto e alterado sem provocar mudança no mudo exterior. Atividades como as mencionadas podem servir para a formação de "enclaves" (BERGER; LUCKMANN, 2005), com a transposição de elementos do universo científico para aquele dos estudantes.

Outra possibilidade seria investir em discussões históricas, filosóficas e sociológicas sobre a ciência, tal como proposto por Matthews (1994), Barra (1998), Lederman (2007), Martins (2015) entre outros. Isso também pode contribuir para o esclarecimento daquilo que estabelecem os campos científico e cotidiano, com seus desacordos epistemológicos. Essas discussões podem igualmente fornecer uma compreensão sobre as características da ciência, como seu conhecimento é construído e validado, o que inclusive faria um contraponto a visões equivocadas e ingênuas sobre ela (LEDERMAN, 1992; FERNANDEZ et al., 2002).

Por fim, também consideramos importantes as discussões mais explícitas sobre os movimentos negacionistas, sobretudo esclarecendo seus critérios epistemológicos restritos, que poderiam ser examinados, discutidos e até confrontados.

Essas são apenas algumas ideias gerais. Convém mencionar que a disseminação de movimentos negacionistas e desinformativos nas proporções atuais é um fenômeno novo, que necessita de investigações e reflexões para sua compreensão, e que propostas educacionais que tratam deles ou de suas características ainda precisam ser construídas.

\section{Considerações finais}

A crise epistemológica vinda da perda de confiança nas instituições tradicionais da sociedade, relacionada à primazia das experiências pessoais - aspectos esses que ganharam bastante importância nos dias de hoje -, são elementos que fazem parte do fenômeno do terraplanismo na atualidade. 
A relação com o mundo por meio de experiências diretas, suspendendo-se a dúvida de que ele e os objetos possam ser diferentes do que parecem ser, é parte integrante de nossas formas de vivenciá-lo no âmbito da realidade cotidiana. É o campo em que atuamos nas atividades diárias, aquele que foi denominado por Schutz de "realidade primordial". Já no campo das teorizações científicas há um modo distinto de se relacionar com o mundo, onde a pessoalidade e certos sistemas de significação são postos de lado, ganhando destaque outras formas de conceituar a realidade.

A crença em uma Terra plana tem como uma de suas bases a utilização das evidências dos sentidos como um critério epistemológico que não é posto em contestação, até mesmo para avaliar o que se situa no campo científico. Isso leva a uma atitude de rejeição à ciência, uma vez que ela muitas vezes trata daquilo que não pode ser diretamente percebido ou faz alegações que vão de encontro aos sentidos. Essa rejeição pôde ser identificada nos exemplos de ideias de adeptos do terraplanismo aqui retratadas.

Não podemos negar que o apelo a experiências pessoais possui certa atratividade, já que está em sintonia com o campo mais evidente de realidade, o cotidiano. A atitude natural experiencia o mundo como algo não problemático, sendo que o campo da vida cotidiana e sua epoché funcionam como referência para os indivíduos e suas elaborações sobre como as coisas são. Contudo, no campo da ciência essa epoché é posta de lado e ao pensarmos nos processos educacionais relacionados à Física ou às ciências naturais, é fundamental considerarmos a necessidade de se levantar questionamentos em relação aos critérios epistemológicos da atitude natural.

Consideramos importante que professores de ciências se apropriem do fenômeno da crescente disseminação de movimentos negacionistas e anticientíficos como o terraplanismo. Ignorá-los pode contribuir para que continuem crescendo. Por isso, colocar luz sobre esses movimentos, buscando compreender suas características e discuti-las com estudantes, parece ser uma necessidade no ensino de ciências, principalmente sob ponto de vista epistemológico, esclarecendo seus critérios simplificadores e limitantes.

Apesar de não haver uma solução pronta, é importante neste momento que a questão do negacionismo seja objeto de reflexão, principalmente nos processos educacionais. Ele é fruto de uma crise epistemológica mais profunda, que deu margem para o crescimento de movimentos anticientíficos, que precisam ser enfrentados.

\section{Referências bibliográficas}

A TERRA É PLANA. Direção: Daniel J. Clark. Produção: Delta-V Productions. Estados Unidos: Netflix, 2018.

ALBUQUERQUE, A.; QUINAN, R. Crise epistemológica e teorias da conspiração: o discurso anti-ciência do canal "professor terra plana". Revista Mídia e Cotidiano, v. 13, n. 3, p. 83-104, 2019. 
AQUINO, V. Brasil tem 16 estados com surto ativo de sarampo. Agência Saúde. 13 de setembro de 2019. Disponível em: <http://www.saude.gov.br/noticias/agencia-saude/45790campanha-de-vacinacao-contra-sarampo-ocorrera-em-duas-etapas-no-pais $>$. Acesso: 28 jan. 2020.

BARRA, E. S. O. A realidade do mundo da ciência: um desafio para a história, a filosofia e a educação científica. Revista Ciência e Educação, v. 5, n. 1, p. 15-26, 1998.

BEDFORD, H. Sarampo: Como uma doença evitável retornou do passado. BBC News Brasil. 8 de abril de 2019. Disponível em: <https://www.bbc.com/portuguese/geral47831375>. Acesso: 29 jan. 2020.

BERGER, P.; LUCKMANN, T. A construção social da realidade: tratado de sociologia do conhecimento. Tradução: Floriano de Souza Fernandes. 25. ed. Petrópolis: Vozes, 2005.

CAVAlCANTI, L. Fake News: Memórias de mercenários. Correio Brasiliense. 2018. Disponível em: <https://especiais.correiobraziliense.net.br/fakenews/index2.html>. Acesso: 28 jan. 2020.

CHALMERS, A. F. A fabricação da ciência. São Paulo: Fundação Editora da UNESP, 1994.

DAVIES, W. Why can't we agree on what's true any more? The Guardian. 19 de setembro de 2019. Disponível em: <https://www.theguardian.com/media/2019/sep/19/why-cant-weagree-on-whats-true-anymore>. Acesso em: 6 jun. 2020.

FERNÁNDEZ, I.; GIL, D.; CARRASCOSA, J.; CACHAPUZ, A. e PRAIA, J. Visiones deformadas de la ciencia transmitidas por la enseñanza. Enseñanza de las Ciencias, v. 20, n. 3, p. 477-488, 2002.

FIOCRUZ - Fundação Oswaldo Cruz. Estudo identifica principais fake news relacionadas à Covid-19. 21 de maio de 2020. Portal Fiocruz. Disponível em:

$<$ https://portal.fiocruz.br/noticia/estudo-identifica-principais-fake-news-relacionadas-covid19>. Acesso em: 11 jun. 2020.

GARCIA, R. 7\% dos brasileiros afirmam que Terra é plana, mostra pesquisa. Folha de São Paulo. 14 de julho de 2019. Disponível em:

$<$ https://www1.folha.uol.com.br/ciencia/2019/07/7-dos-brasileiros-afirmam-que-terra-eplana-mostra-pesquisa.shtml>. Acesso: 3 mar. 2020. 
GUPTA, A.; HAMMER, D.; REDISH, E. F. The Case for Dynamic Models of Learners' Ontologies in Physics. Journal of the Learning Sciences, v. 19, n. 3, p. 285-321, 2010.

HOOTSuite; WE ARE SOCIAL. Digital 2019 Global Digital Overview. 2019a. Disponível em: <https://datareportal.com/reports/digital-2019-global-digital-overview>. Acesso: 28 jan. 2020.

HOOTSUITE; WE ARE SOCIAL. Digital 2019 Brazil. 2019b. Disponível em: $<$ https://datareportal.com/reports/digital-2019-brazil>. Acesso: 28 jan. 2020.

INTERVOZES. Coletivo Brasil de Comunicação Social. Desinformação: ameaça ao direito à comunicação muito além das fake news. 2019. Disponível em:

$<$ https://app.rios.org.br/index.php/s/p9HoCNpPoPYQJc5>.

LEDERMAN, N. G. Student's and teacher's conceptions of the nature of science: a review of the research. Journal of Research in Science Teaching, v. 29, n. 4, p. 331-359, 1992.

LEDERMAN, N. G. Nature of science: past, present, and future. In: ABELL, S. K.; LEDERMAN, N. G. (eds.). Handbook of research on science education. Mahwah, New Jersey: Lawrence Erlbaum Associates, 2007. p. 831-879.

MARTINS, A. F. P. Natureza da Ciência no ensino de ciências: uma proposta baseada em “temas" e "questões". Caderno Brasileiro de Ensino de Física, v. 32, n. 3, p. 703-737, 2015.

MARTINS, I.; OGBORN, J.; KRESS, G. Explicando uma explicação. Ensaio: Pesquisa em Educação em Ciências, v. 1, n. 1, p. 29-46, 1999.

MATTHEWS, M. R. Science Teaching: The Role of History and Philosophy of Science. New York: Routledge, 1994.

MICHALSKI, R.; PAULA, L. T. Os bots de disseminação de informação na conjuntura das campanhas presidenciais de 2018 no Brasil. Múltiplos Olhares em Ciência da Informação, v. 9, n. 1, p. 1-16, 2019.

OXFORD DICTIONARY. Oxford Dictionary 2016 word of the year. 2016. Disponível em: $<$ https://en.oxforddictionaries.com/word-of-the-year/word-of-the-year-2016>. 
PAULA, L. T.; SILVA, T. R. S.; BLANCO, Y. A. Pós-verdade e Fontes de Informação: um estudo sobre fake news. Revista Conhecimento em Ação, v. 2, n. 1, p. 93-110, 2018.

PIETROCOLA, M. Construção e realidade: o realismo científico de Mário Bunge e o ensino de ciências através de modelos. Investigações em ensino de ciências, v. 4, n. 3, p. 213-227, 1999.

PINHEIRO, T. F.; PIETROCOLA, M.; PINHO-ALVES, J. Modelização de variáveis: uma maneira de caracterizar o papel estruturador da Matemática no conhecimento científico. In: PIETROCOLA, M. (Org.). Ensino de Física: conteúdo, metodologia e epistemologia numa concepção integradora. Florianópolis: Editora da UFSC, 2001. p. 33-52.

SCHUTZ, A. On Multiple Realities. In: SCHUTZ, A. Collected Papers I. The Problem of Social Reality. The Hague: Martinus Nijhoff, 1962. p. 207-259.

TIERCELIN, C. Verbete "Realisme". In: LECOURT, D. (Org). Dictionnaire d'histoire et philosophie des sciences. Paris: Puf, 1999. 